\section{Advisers to the nation}

$\mathrm{H}$

ealth care leaders and re-

searchers have united to

create Canada's first na-

tional health advisory body. Modelled on the US Institute of Medicine, the Canadian Academy of Health Sciences (CAHS) will advise policy-makers, the public and public- and private-sector leaders.

"Other countries have benefited from having an organization at arm's length from government to provide objective advice on emerging issues," says Dr. Martin Schechter, presidentelect of the Academy.

"We keep reinventing committees to address emerging issues, whereas the IOM is ready to go when an issue arises," says the head of the Department of Health Care and Epidemiology at the University of British Columbia.

CAHS is I of 3 "virtual" bodies that constitute the Canadian Academies of Science, which have been allocated \$35 million over ro years in federal funding. CAHS is seeking funding for infrastructure, staffing and travel costs. Clients will pay for reports.

In his 2004 Throne Speech, Prime Minister Paul Martin called the Academy "a source of expert advice on scientific aspects of important domestic and international issues."

The initial lack of funds won't slow the organization down, says Schechter. "If there is funding to conduct an assessment, we can do it."

CAHS members are drawn from medicine, nursing, pharmacy, dentistry, rehabilitation science and veterinary medicine. The interdisciplinary nature of the Academy makes it unique, says Schechter. He hopes their first project will assess the barriers to and benefits of fostering interdisciplinary health research.

"We have a partnership that involves all the health disciplines and the full spectrum of research, from test tube to population health. We really are going to be 'advisers to the nation."'

The Academy held its inaugural meeting Sept. 2I in Vancouver. - Sally Murray, CMAJ

\section{News@a glance}

Chemical exposures: The US Centers for Disease Control and Prevention is reporting on public exposure to 38 new chemicals in its Third National Report on Human Exposure to Environmental Chemicals. For the first time, reference ranges of chemicals, including dieldrin and pyrethroid insecticides, are available for use by public health officials. The report, which was released by the CDC National Center for Environmental Health, uses biomonitoring measuring chemicals or their metabolites directly in blood or urine to assess average exposure to chemicals in randomly selected participants. It assesses 148 chemicals. New data indicate $5 \%$ of the US population aged 20 years or older had urinary cadmium at levels that may be associated with kidney injury and risk of low bone-mineral density.

Nursing centennial: Canadian Nurse celebrated its rooth anniversary in September. The first issue of Canada's oldest peer-reviewed nursing journal was sponsored by the alumnae of the Toronto General Hospital. It became a national publication in 1924 and now has a circulation of 123 I00.

Infected hamster: The Center for Disease Control in Washington has traced the source of a viral infection that killed 3 transplant patients to a pet hamster. Four patients became infected with lymphocytic choriomeningitis virus (LCMV) from a common organ donor; 3 died in the weeks after transplantation. LCMV infection is usually mild but can cause meningitis in persons with immune system defects. It can also cause severe defects in a fetus in the first and second trimester of preg-

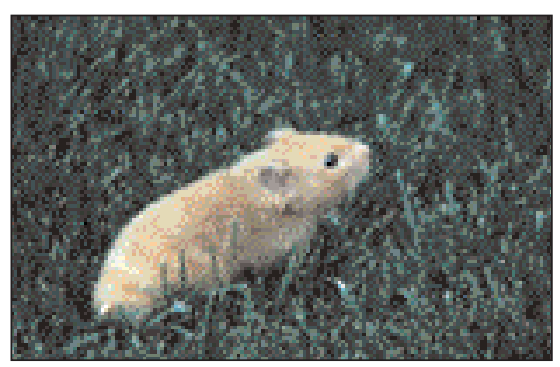

nancy. The hamster was purchased in a Rhode Island store, where testing of other rodents identified 3 other LCMVinfected animals (I guinea pig and 2 hamsters). MidSouth Distributors in Ohio, which supplied the rodents, has quarantined and is destroying its animals. Officials are now tracing other infected rodents sent across the US since February. (See related article, Public Health.)

Newborn screening: Ontario is adding I9 tests for inherited metabolic disorders; the province now screens for only 2 diseases (CMAJ 2005;173:23). California tests for 75 .

Blood needed: Canada needs an estimated 80 ooo new blood donors this year to build a "long-lasting and sufficient donor base," says the Canadian Blood Services. According to an Ipsos Reid survey, $52 \%$ of Canadians or one of their family members needed blood or blood products in the past, yet less than $4 \%$ of the eligible population donated last year. "This should be a wake-up call for Canadians," said Dr. Graham Sher, CEO of Canadian Blood Services. Call $888236-6238$ to donate.

I love olive: Researchers in Australia believe extra-virgin olive oil may produce ibuprofen-like anti-inflammatory activity. Despite structural differences from ibuprofen, biologist Gary Beauchamp and colleagues reported in the September I issue of Nature that oleocanthal, a compound found in newly pressed extra-virgin olive oil, inhibits the same cyclooxygenase (COX) enzymes that cause inflammation. The researchers confirmed their findings by isolating oleocanthal from olive oil and then synthesizing it in the laboratory, noting that it inhibited COX-I and COX-2 activity in a dose-dependent way. Their findings raise the possibility that olive oil could work in low doses to prevent heart disease, like aspirin. It may also explain why the Mediterranean diet, rich in olive oil, offers health benefits such as reduced cardiovascular risk. Compiled by Sally Murray, $C M A J$

DOI:I0.1503/cmaj.051182 